(RESEARCH ARTICLE)

\title{
Antidiabetic and antioxidant effects of Lupinus albus L. seed roasting ethanol extract in streptozotocin diabetic rats
}

\author{
Betul Apaydin Yildirim 1, ${ }^{*}$, Ali Ertekin ${ }^{2}$, Saban Kordali ${ }^{3}$ and Serkan Yildirim ${ }^{4}$ \\ ${ }^{1}$ Department of Biochemistry, Faculty of Veterinary, Ataturk University, Erzurum/Turkey. \\ 2 Department of Biochemistry, Faculty of Veterinary, Ondokuz Mayis University, Samsun/Turkey. \\ ${ }^{3}$ Mugla Sitki Kocman University, Faculty of Agriculture, Department of Plant Protection, Fethiye-Mugla, Turkey. \\ ${ }^{4}$ Department of Pathology, Faculty of Veterinary, Ataturk University, Erzurum/Turkey.
}

Publication history: Received on 08 July 2020; revised on 05 August 2020; accepted on 06 August 2020

Article DOI: https://doi.org/10.30574/wjarr.2020.7.2.0251

\begin{abstract}
Diabetes mellitus (DM) may cause specially health problem which can effect most of tissue such as liver, kidney and brain. Thus, this research aimed to examining the effects of Lupinus albus L. seed ethanol extract (LA) on the liver and renal tissues malondialdehyde (MDA), catalase (CAT), superoxide dismutase (SOD), glutathione peroxidase (GPx) and glutathione (GSH) level of diabetic rats. Sprague-Dawley, adult a total of 28 male rats were used in the study that were randomly divided into four groups with 7 animals in each group: Control, STZ-DM, LA and STZ-DM+LA group. Diabetes was induced in rats by a single dose of $60 \mathrm{mg} / \mathrm{kg} / \mathrm{i} . \mathrm{p}$. Streptozotocin (STZ) injection (STZ-DM and STZ-DM+LA groups). Lupinus albus L. ethanol extract was given at a dose of $10 \mathrm{mg} / \mathrm{kg} / \mathrm{p} .0$. via intragastric tube for 20 days (LA and STZDM+LA groups). At the end of the study, biochemical and histopathological examination in kidney and liver tissues were examined. STZ application significantly increased the oxidative stress and lipid peroxidation. When the dose of 10 $\mathrm{mg} / \mathrm{kg}$ of LA significantly decreased the level of plasma glucose and liver and renal MDA. Meanwhile, the levels of liver and renal CAT, SOD, GPX and GSH were significantly increased in diabetic rats treated with Lupinus albus L. seed ethanol extract. These results indicate the role of Lupinus albus L. seed extract might as antidiabetic, antioxidant and reducing of the oxidative stress and lipid peroxidation. Extracted after Lupinus albus seed' roasting is a pioneer in literature and the use of LA in ethnomedicine for diabetes.
\end{abstract}

Keywords: Antioxidants substances; Diabetes; Lipid peroxidation; Lupinus albus L.

\section{Introduction}

Diabetes mellitus (DM) is a public health problem that is a global epidemic with a generality of 246 million ( $46 \%$ affected in the 40-59 age) in 2007, is expected to rise to $380 \mathrm{~m}$ by 2025 [1]. DM comprises a group of common metabolic diseases characterized by chronically hyperglycemia because of patients have varying cellular homeostasis and disorganization in insulin levels which causes widespread vascular injury and multiple tissue failure. Insulinemia and glycemia levels should be inspected to prevent unwanted conditions caused by diabetes. Lately, many ethnobotanical researches in varied parts of the world have shown that empirical used more than 1200 plants in DM treatment [2]. The antidiabetic effect of plant extracts could be dependent encouragement insulin secretion and $\beta$-cells situated insulin impact [3].

Some of the Lupine species extracts have been used to phytotherapy [4]. Lupinus albus L. species is Lupinus genus, Leguminosae or Fabaceae family. Lupinus albus L. seeds are very plenty in dietary fiber and proteins, are almost independent of phytoestrogens and starch, and include many antioxidant, minerals, essential amino acids and lipids. Lupinus albus L. seed proteins are also supposed to discharge some of the bioactive peptides playing prominent roles in scrambling cardiovascular diseases, diabetes and obesity. The seeds typically involve 6-13\% oil, 34-39\% fibers and 33-

\footnotetext{
${ }^{*}$ Corresponding author: Betul Apaydin Yildirim
} 
$47 \%$ proteins $[5,6]$. Lupinus protein provides various health benefits, specially in the area of cholesterol reduction, hyperglycaemia or hypertension prevention [7].

Various reactive nitrogen and oxygen species are producted by the oxygen metabolism. Peroxynitrite is a representative reactive nitrogen species and peroxyl radical, hydrogen peroxide, hypochlorite ion, hydroxyl radical and superoxide anion are typical ROS [8]. ROS include nucleic acids, proteins, lipids and carbohydrates. Malondialdehyde (MDA) is one of the examples of the end products from the oxidation reactions involving lipids and a toxic molecule, regarded as a biomarker of oxidative stress [9]. Oxidative stress which based on the imbalance of antioxidant enzymes and ROS production. It may induce damage of nucleic acids, proteins, lipids and tissue. Therefore it plays a sensitive role in environment involved diseases in humans including respiratory diseases, cancer, arteriosclerosis and asthma [10]. Antioxidants have a wide range of effects in various disease conditions and help to prevent the onset of such conditions. Natural antioxidants that occur in an organism could fight against the oxidative stress that occurs through various physiologic processes. CAT, SOD, GPx and GSH which are endogenous antioxidants. In particular, glutathione plays a fundamental role in defense in case of oxidative stress [9].

This study mainly focused on the investigation of the Lupinus albus L. seed ethanol extract on anti-oxidative and antihyperglisemic effect on diabetes management.

\section{Material and methods}

\subsection{Preparation of the Lupinus albus L. extract}

Lupinus albus L. seed materials which purchased from spice shop and dried under shade. We roasted all of seed material and powdered before extraction. $100 \mathrm{~g}$ of powder was added into $500 \mathrm{~mL}$ ethanol for 48 hours and then filtered. Ethanol extracted were evaporated under vacuum $\left(40^{\circ} \mathrm{C}\right.$ with a rotary evaporator). The evaporation-dried extracts of organic solvents at reduced pressure and temperature were stored at $4{ }^{\circ} \mathrm{C}$ until use. The extract was dissolved in $1 \mathrm{~mL}$ distilled water before application. The extract were applied to animals $(10 \mathrm{mg} / \mathrm{kg}, \mathrm{b} . \mathrm{w})$ by using a intragastric tube for 20 days.

\subsection{Animals and experimental design}

Sprague Dawley rats weighing 200-250 g male rats were purcased from the Center of laboratory animals, ATADEM, Erzurum, Turkey. The ethical norms were obtained prior to start study for Ethic Committee (No: 06.03.2014 36643897203-ATA-44 Turkey/Erzurum). All of rats were used under standardized animal housing condition (12 h light/12h dark, $25 \pm 2{ }^{\circ} \mathrm{C}$, standard water and pelet diet ad libitum). Rats were fasted $18 \mathrm{~h}$ before from the experiments, but had free access to water. Animals were divided into 4 groups of 7 rats each Control Group: Untreated normal rats, STZ-DM Group: Diabetic rats were received single dose of Streptozotocin $60 \mathrm{mg} / \mathrm{kg} / \mathrm{i} . \mathrm{p}$., LA Group: Only received Lupinus albus $L$. ethanol extract dose of $10 \mathrm{mg} / \mathrm{kg} /$ p.o. dissolved in $1 \mathrm{~mL}$ distilled water via intragastric tube once a day for 20 days. STZDM+LA Group: Diabetic rats were given single dose of STZ 60 mg/kg/i.p. + LA $10 \mathrm{mg} / \mathrm{kg} /$ day/p.o. dissolved in $1 \mathrm{~mL}$ distilled water via intragastric tube once a day for 20 days.

\subsection{Induction of diabetes}

Diabetes was induced in Spraque Dawley rats by intraperitoneal injection administration of a single (60 mg/kg b.w.) of STZ (Sigma) dissolved in dissolved in citrate buffer ( $0.1 \mathrm{M}, \mathrm{pH} 4.5)$. After seven days of injection, the blood glucose levels were measured from tail vein (indicated by Bayer's glucometer-elite commercial test based on glucose oxidase method) and a blood glucose level above $250 \mathrm{mg} / \mathrm{dL}$ were used for this study as diabetic.

All of rats of four groups were sacrificed by cervical decapitation on $20^{\text {th }}$ day and liver and renal tissues dissected out washed by ice cold phosphate buffer saline solution (pH 7.2 PBS) to remove excess blood etc. And stored at $-80^{\circ} \mathrm{C}$ until used for biochemical analysis. Tissues was homogenized using Qiagen TissueLyserII. MDA [11] levels, CAT [12], SOD [13] and GPx [14] activities and reduced GSH [15] levels were measured in liver and renal tissues of the rats. Pancreas, liver and renal tissues were taken from all groups and were removed and immediately half of them were fixed in $10 \%$ formalin for $48 \mathrm{~h}$. After dehydration in a graded ethanol series and clearing with xylene, the sample material was embedded in paraffin and serial sections of 4- $\mu \mathrm{m}$ in thickness were cut using microtome and stained using the Haematoxylin-Eosin stain for observation under the light microscope [16]. The sections were examined by using an Leica DM 1000 light microscope and all specimen examined in 10 randomly selected areas of approximately x40 objective. The scores were derived semi-quantitatively using light microscopy on the preparations from each animal and were graded as follows: none $(-)$; mild $(+)$; moderate $(++)$ and severe $(+++)$. 


\subsection{Statistical analysis}

The data were analysed by one-way analysis of variance (ANOVA) followed using the statistical package for social science SPSS software version 22.0 program (IBM software, Inc. Chicago, USA), Duncan's multiple range test applied and represented as mean \pm standard deviation $(\mathrm{SD})(\mathrm{P}<0.05)$.

\section{Results}

\subsection{Biochemical findings}

Glucose levels of the control and experimental groups are shown in Table 1. In the Table 2-3 the liver and kidney tissues levels of CAT activities, MDA levels, SOD, GPx activities and GSH levels are shown.

Table 1 Glucose levels of the control and experimental groups.

\begin{tabular}{lllll}
\hline Glucose (mg/dL) & & \\
\hline Control Group & STZ-DM Group & LA Group & STZ-DM+LA Group & P \\
\hline $126.00 \pm 1.03^{\mathrm{b}}$ & $450.00 \pm 1.29^{\mathrm{a}}$ & $122.50 \pm 1.12^{\mathrm{b}}$ & $125.83 \pm 1.22^{\mathrm{b}}$ & $* * *$ \\
\hline \multicolumn{5}{c}{ a,b Means superscripted with different letters are significantly different $\left(^{* * *} \mathrm{P}<0.001\right)$} \\
STZ-DM: Diabetes, LA: Lupinus albus L. ethanol extract, STZ-DM+LA: Treatment group.
\end{tabular}

Table 2 CAT, MDA, SOD, GPx activities and GSH levels of control and experimental groups in liver tissue.

\begin{tabular}{|c|c|c|c|c|c|}
\hline Groups & $\begin{array}{l}\text { CAT } \\
\text { tissue })\end{array}$ & $\begin{array}{l}\text { MDA (nmol/g } \\
\text { tissue) }\end{array}$ & $\begin{array}{l}\text { SOD (EU/mg } \\
\text { protein) }\end{array}$ & $\begin{array}{l}\text { GPx } \quad(U / \mathbf{m g} \\
\text { protein) }\end{array}$ & $\begin{array}{l}\text { GSH (mmol/g } \\
\text { tissue) }\end{array}$ \\
\hline Control (Liver) & $167.32 \pm 6.57 \mathrm{~b}$ & $31.69 \pm 1.19^{b}$ & $24.09 \pm 0.35^{\mathrm{a}}$ & $5.79 \pm 0.38$ & $4.39 \pm 0.08^{\mathrm{ab}}$ \\
\hline STZ-DM (Liver) & $127.13 \pm 0.97 \mathrm{c}$ & $55.63 \pm 1.53^{\mathrm{a}}$ & $20.65 \pm 0.30^{b}$ & $5.14 \pm 0.20$ & $4.23 \pm 0.16^{b}$ \\
\hline LA (Liver) & $183.57 \pm 2.61^{\mathrm{a}}$ & $28.62 \pm 1.09^{b}$ & $24.58 \pm 0.57^{\mathrm{a}}$ & $5.64 \pm 0.38$ & $4.79 \pm 0.04^{\mathrm{a}}$ \\
\hline $\begin{array}{l}\text { STZ-DM+LA } \\
\text { (Liver) }\end{array}$ & $166.57 \pm 2.47^{b}$ & $33.31 \pm 1.96^{b}$ & $23.75 \pm 1.11^{\mathrm{a}}$ & $5.22 \pm 0.22$ & $4.54 \pm 0.19^{\mathrm{ab}}$ \\
\hline $\mathrm{P}$ & $* * *$ & $* * *$ & $* *$ & NS & $*$ \\
\hline
\end{tabular}

Table 3 CAT, MDA, SOD, GPx activities and GSH levels of control and experimental groups in kidney tissue.

\begin{tabular}{|c|c|c|c|c|c|}
\hline Groups & $\begin{array}{c}\text { CAT (kU/g } \\
\text { tissue) }\end{array}$ & $\begin{array}{c}\text { MDA (nmol/g } \\
\text { tissue) }\end{array}$ & $\begin{array}{l}\text { SOD }(\mathrm{EU} / \mathrm{mg} \\
\text { protein) }\end{array}$ & $\begin{array}{c}\text { GPx }(\mathrm{U} / \mathbf{m g} \\
\text { protein) }\end{array}$ & $\begin{array}{c}\text { GSH (mmol/g } \\
\text { tissue) }\end{array}$ \\
\hline $\begin{array}{l}\text { Control } \\
\text { (Kidney) }\end{array}$ & $163.94 \pm 1.69^{a}$ & $140.17 \pm 2.51^{b c}$ & $10.70 \pm 0.29^{b}$ & $4.40 \pm 0.17$ & $4.92 \pm 0.34^{a}$ \\
\hline $\begin{array}{l}\text { STZ-DM } \\
\text { (Kidney) }\end{array}$ & $122.35 \pm 1.10^{c}$ & $157.14 \pm 1.46^{\mathrm{a}}$ & $7.51 \pm 0.40^{c}$ & $4.13 \pm 0.04$ & $3.99 \pm 0.10^{b}$ \\
\hline LA (Kidney) & $164.96 \pm 1.34^{\mathrm{a}}$ & $134.89 \pm 1.55^{c}$ & $12.24 \pm 0.40^{\mathrm{a}}$ & $4.86 \pm 0.22$ & $4.80 \pm 0.09^{a}$ \\
\hline $\begin{array}{l}\text { STZ-DM+LA } \\
\text { (Kidney) }\end{array}$ & $157.03 \pm 2.32^{\mathrm{b}}$ & $142.90 \pm 2.10^{\mathrm{b}}$ & $11.04 \pm 0.42^{\mathrm{ab}}$ & $4.51 \pm 0.34$ & $4.56 \pm 0.11^{\mathrm{ab}}$ \\
\hline $\mathbf{P}$ & $* * *$ & $* * *$ & $* * *$ & NS & $* *$ \\
\hline
\end{tabular}




\subsection{Histopathological Findings}

Histopathological evaluation of the liver, kidney and pancreas tissues are presented in Table 4-5. Histological appearance of the liver, kidney and pancreas tissues are presented in Figure 1-3.

Control Group: The liver tissues of the rats in this group were found to be in normal histological structure (Figure $1 \mathrm{~A}$ ).

STZ-DM Group: Degeneration and coagulation necrosis of hepatocytes in the acinar region were determined in the liver tissues of rats in this group. Sinusoids and veins were dilated and hyperemic (Figure 1 B).

LA Group: It was determined that the liver tissues of this group had normal histological appearance (Figure 1 C).

STZ-DM+LA Group: A small number of hepatocyte degeneration was observed in the liver tissues of rats in this group. Sinusoids and veins were slightly dilated and hyperemic (Figure 1 D). Histopathologic evaluations are summarized in Table 4 .
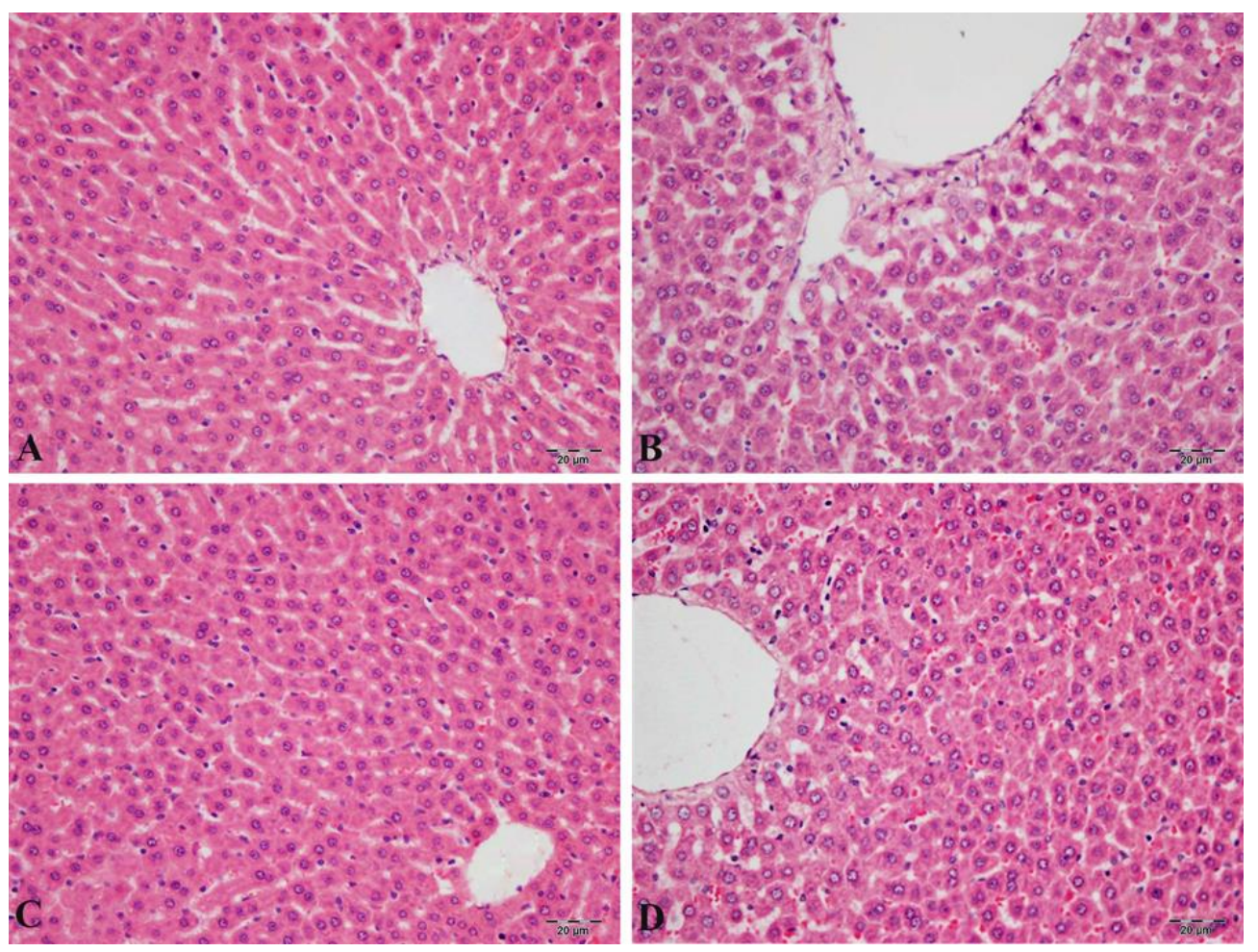

Figure 1 Effect of LA on histology of liver tissue in diabetic rats.

Control group (A): Normal histological structure of the liver; STZ-DM (B), degeneration and necrosis in hepatocytes in the acinar region, sinusoids dilate and hyperemic; LA group (C), normal histological appearance of the liver; STZ-DM+LA group (D), very few hepatocyte degeneration, sinusoidal hyperemia, H\&E, Bar: $20 \mu \mathrm{m}$.

Table 4 Histopathological evaluation of the liver tissue.

\begin{tabular}{llll}
\hline Groups & Degeneration in hepatocytes & Necrosis in hepatocytes & Hyperemia in veins \\
\hline Control & - & - & - \\
STZ-DM & +++ & ++ & +++ \\
LA & - & - & - \\
STZ-DM+LA & ++ & - & + \\
\hline & STZ-DM: Diabetes, LA: Lupinus albus L. ethanol extract, STZ-DM+LA: Treatment group.
\end{tabular}


Control Group: The kidney tissues of the rats were found to be in normal histological structure (Figure $2 \mathrm{~A}$ ).

STZ-DM Group: The kidney tissues of rats were examined, dilation in tubulus and bowman capsule, necrosis in tubulus epithelium and severe degeneration, hyperemia in veins and glomerulus were observed. (Figure 2 B).

LA Group: It was determined that the kidney tissues of this group had normal histological appearance (Figure $2 \mathrm{C}$ ).

STZ-DM+LA Group: In the tubulus epithelium of the kidney tissue were found a few hydropic degenerations. Necrotic cell was never found. Mild hyperemia was seen in interstitial vessels and glomerulus (Figure 2 D). Histopathologic evaluations are summarized in Table 5.

Table 5 Histopathological evaluation of kidney tissue.

\begin{tabular}{lllll}
\hline Groups & $\begin{array}{l}\text { Interstitial } \\
\text { nephritis }\end{array}$ & $\begin{array}{l}\text { Degeneration } \\
\text { tubul epithelium }\end{array}$ & $\begin{array}{l}\text { Necrosis in tubul } \\
\text { epithelia }\end{array}$ & Hyperemia in veins \\
\hline Control & - & - & - & - \\
STZ-DM & ++ & +++ & +++ & +++ \\
LA & - & - & - & - \\
STZ-DM+LA & + & ++ & - & ++ \\
\hline
\end{tabular}
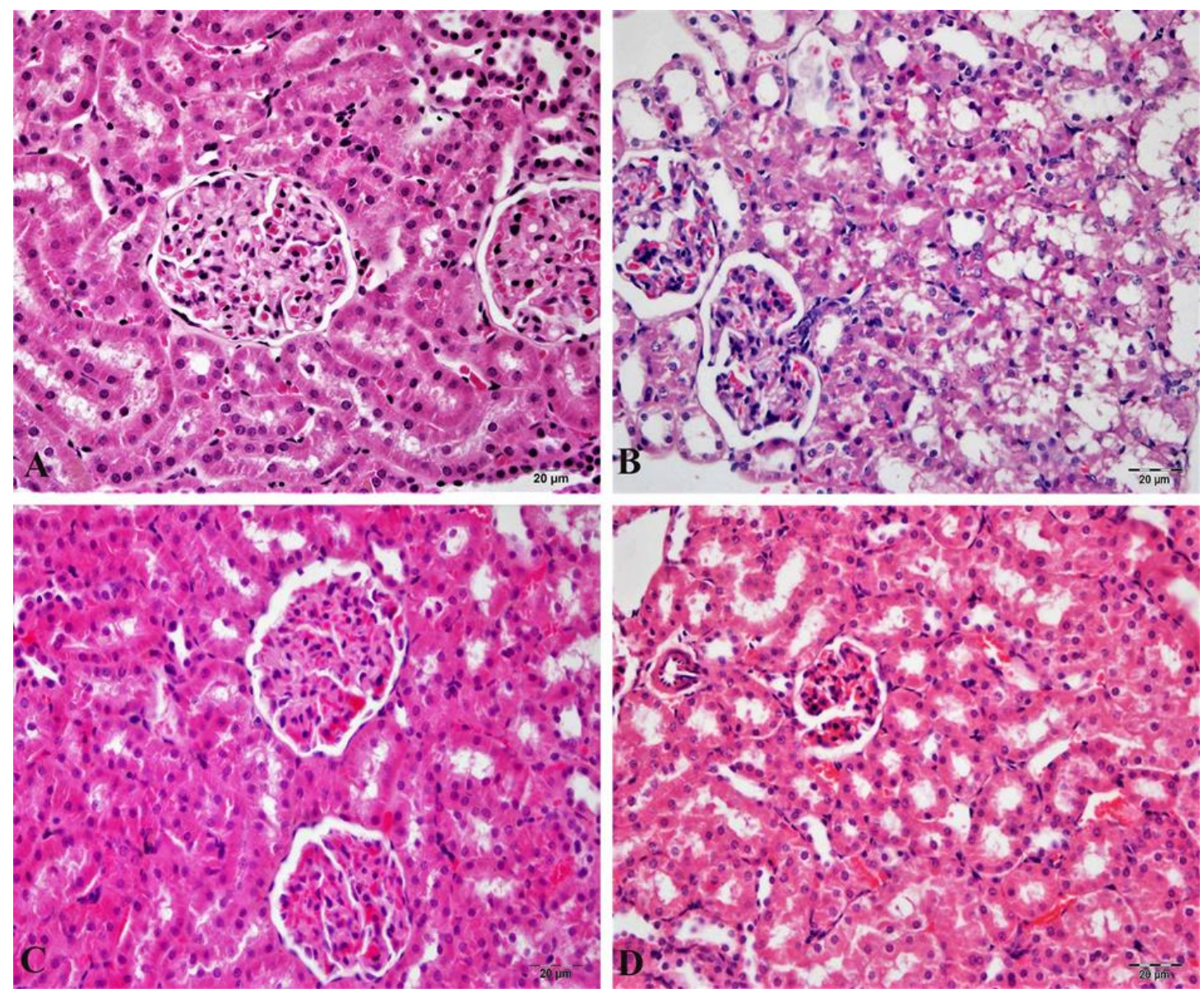

Figure 2 Effect of LA on histology of kidney tissue in diabetic rats

Control group (A): Normal histological structure of the kidney; STZ-DM group (B), hydropic degeneration and coagulation necrosis in tubul epithelia, hyperemia in intertubular arterioles and glomerulus, dilatation in bowman 
capsule and some tubules; LA group (C), normal histological appearance of the kidney; STZ-DM+LA group (D), degeneration in tubul epithelia and hyperemia in intertubular veins, H\&E, Bar: $20 \mu \mathrm{m}$.
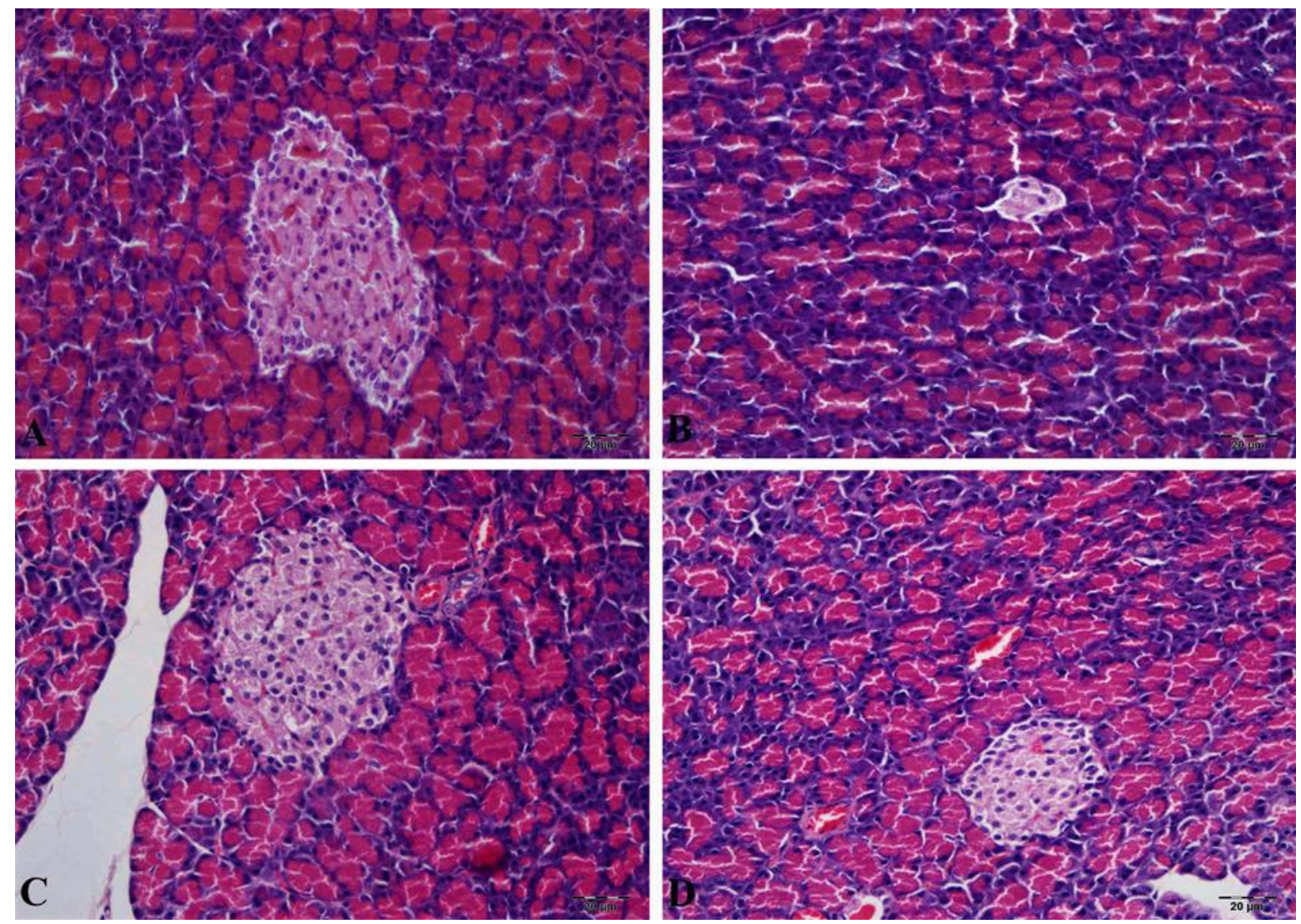

Figure 3 Effect of LA on histology of pancreas tissue in diabetic rats.

Control group (A): Normal histological structure of the pancreas; STZ-DM group (B), severe atrophy in langerhans islets, degeneration and necrosis in islet cells; group (C), normal histological appearance of the pancreas; STZ-DM+LA group (D), small number of degeneration and necrosis in islet cells, H\&E, Bar: $20 \mu \mathrm{m}$.

\section{Discussion}

Diabetes mellitus is a chronic metabolic syndrome with hyperglycemia. It consists because of insulin deficiency/resistant, and ends up with disregulation of protein, carbohydrate and lipid metabolism. Diabetes mellitus is widespread chronic disease. Genetic and environmental factors act together on development of diabetes mellitus [17].

Oxidative stress has been defined disturbance in balance between the production of free radicals or ROS and antioxidant defence system. The ROS includes both free radicals (molecules having a hydroxyl radical, superoxide radical anion and odd electron) and ozone, singlet oxygen and hydrogen peroxide that are not free radicals [18].

Oxidative stress can play a sensitive role in the progression and onset of diabetes mellitus [19]. In diabetes, increased in speedly molecular damage, efficiently species and substrate for these oxidative reactions result from dyslipidemia and hyperglycemia which can work as both mechanisms and markers of DM disease [20].

Blood glucose levels were increased in diabetic control rats $(\mathrm{p}<0.001)$. When treated with Lupinus albus L. seed ethanol extract diabetic rats showed significantly $(\mathrm{p}<0.001)$ decreased blood glucose levels, close to the normal levels $($ Table 1$)$.

The measurement of MDA levels in biological samples has been widely used since MDA has been recognized as a lipid peroxidation marker in the last 20 years. Diabetes's complications and etiology showed that this disease absolutely one of the more common involving pathologies. Some studies have documented increased lipid oxidation in patients with carbohydrate metabolism disorders ${ }^{21}$. MDA has been confirmed as a lipid peroxidation end product marker. Several investigations have reported elevated MDA levels in diabetes [21,22]. MDA levels of the kidney and liver tissues were 
found to be higher in STZ-DM groups according to control groups in our study $(\mathrm{p}<0.001)$. Possible subclinical complications could play a role in increasing the levels of MDA in diabetes. ROS level increase in diabetes can be due to decrease in destruction or/and increase in the production by CAT, SOD and GPx antioxidants. Oxidative stress is giving rise to improving diabetic complications and sensible tissue due to these enzymes variation [23].

Most studies reported that the seeds of lupin contain flavonoids and phenolic acids. The presence of phenolic acids in lupin seeds is not clear. In this group of phenolic compounds, the main acids may be hydroxybenzoic compounds [24] or or trans-ferulic compounds [25]. It is known that the phenolic compounds increase during the germination period of lupine seeds. The quantitative determination of antioxidant capacity and phenolic compounds content of lupine seeds can reveal the health value of lupine seeds. Three types of lupine having antioxidant properties have been reported, that yellow lupin seeds being more abundant than the narrow-leafed and white lupin seed in terms of flavonoids acid and phenolic acids [26]. MDA levels in LA and STZ-DM+LA groups were lower than STZ-DM group both liver and kidney tissues ( $\mathrm{p}<0.001$ ). MDA levels were lower in the LA group according to another groups. The ethanol extract of Lupinus albus L. seed could help to reduce the levels of oxidative stres in the liver and kidney of diabetic rats via cleaning the free radicals highly removed in diabetes.

Lipid peroxidation is important for diabetes. The free radicals increased due to the damage of antioxidant defence system and lipid peroxidation increased in diabetes. The decreased activity of antioxidant substances go along with removed lipid peroxide levels in diabetic rats could likely be associated with oxidative stres and decreased antioxidant defense demand [27]. Our results showed that in diabetic rats, the levels of lipid peroxidation were high in liver and kidney tissues and may be, were restored to normal values after the lupine extract has been administered.

The measurement of glutathione activity, which is important for detoxification of toxic substances, is considered a particular indicator of oxidative stress or antioxidant status. The measurement of glutathione activity, which is important for detoxification of toxic substances, is thought a well indicator of oxidative stress or antioxidant status. There is an opposing relationship between glutathione levels and oxidative stress [28]. The reduction in glutathione levels $(\mathrm{p}<0.05)$ in STZ-DM group according to control group in this present study may be due to increased usage of this intracellular antioxidant by GPx. This reduction may also be justified due to increased usage of GSH for the inhibited synthesis of glutathione or detoxification of toxicant induced free radicals [29,30]. In this study, glutathione levels in STZ-DM groups were lower than control group liver $(p<0.05)$ and kidney $(p<0.01)$ tissues. In the LA and STZ-DM+LA groups, glutathione levels were higher in liver LA and STZ-DM+LA groups $(\mathrm{p}<0.05)$ compared to STZ-DM and control groups but kidney tissue values were lower $(\mathrm{p}<0.01)$ by control group.

Many scientists think CAT activities is more sensitive and more important than SOD as an oxidative stress biomarker. CAT is the mainly enzyme managing for the protection and protection of the enzymatic antioxidant when increased production of ROS. $\mathrm{H}_{2} \mathrm{O}_{2}$ formed due to the catalytic reaction of SOD, which is both a normal cellular metabolite and a reactive oxygen source, occurs and is detoxified by CAT and GPx [31,32]. In this study represented that CAT activity was significantly reduced in liver and kidney tissues of diabetic rats $(\mathrm{p}<0.001)$. The reduction of CAT activities might be due to inhibition or exhausting due to the increased production of free radicals. But, CAT activity was found to be significantly higher $(\mathrm{p}<0.001)$ in LA and STZ- DM+LA groups according to diabetic rats in liver and renal tissues.

Copper and zinc containing enzyme is SOD that produced with sequent constitution of hydrogen peroxide $\left(\mathrm{H}_{2} \mathrm{O}_{2}\right)$ in the enzymatic antioxidant defence system. This constitude $\mathrm{H}_{2} \mathrm{O}_{2}$ is reduced by a GSH dependent mechanism catalysed by GPx or decomposed by catalase. As a result of an auto-oxidation of superoxide radicals and electron transport chain components are produced in endoplasmic reticulum and mitochondria. SOD converts superoxide into oxygen and hydrogen peroxide [33]. Antioxidant enzyme activity is reduced due to over use in stress conditions that cause free radical formation [34]. The observed decrease in SOD activity in liver $(p<0.01)$ and kidney $(p<0.001)$ tissues of diabetic rats could result from inactivation by $\mathrm{H}_{2} \mathrm{O}_{2}$. In the other groups given Lupinus albus $\mathrm{L}$., SOD activity was increased in liver $(\mathrm{p}<0.01)$ and renal $(\mathrm{p}<0.001)$ tissues by diabetic rats.

GPx defines the general name of an enzyme family with peroxidase activity that protects the organism from oxidative damage [35]. There is a decrease in circulating levels of GPx, which may be caused by the occurrence of oxidative stress in diabetic rats. The changes observed in all groups did not show any significance.

In the present study, we investigated significant decrease in CAT, SOD, GPx activities and GSH levels in diabetic rats. Likely due to hyperglycemia, the synthesis and activity of many antioxidant enzymes, primarily SOD and GPx, are reducted by glycosylation. The role of oxidative stres in the pathogenesis of diabetic nephropathy is not only through over production of ROS but also auto oxidation of glucose, the reduction of antioxidant enzyme activities, formation of 
lipid peroxidase, disrupted GSH metabolism and nonenzymatic protein glycosylation [27]. Lupinus albus L. seed ethanol extract significantly increased antioxidant enzyme activity in diabetic rats.

When we evaluate the histopathological findings, we have observed normal histological structure of the liver in control group, degeneration and necrosis in hepatocytes in the acinar region, sinusoids dilate and hyperemic in STZ-DM group, normal histological appearance of the liver in LA group and very few hepatocyte degeneration, sinusoidal hyperemia in STZ-DM+LA group (Figure 1). We observed normal histological structure in control group, hydropic degeneration and coagulation necrosis in tubul epithelia, hyperemia in intertubular arterioles and glomerulus, dilatation in bowman capsule and some tubules in STZ-DM group, normal histological appearance in LA group and degeneration in tubul epithelia and hyperemia in intertubular veins in STZ-DM+LA group in kidney tissue histopathology (Figure 2). Also we observed normal histological structure of the pancreas in control group, severe atrophy in langerhans islets, degeneration and necrosis in islet cells in STZ-DM group, normal histological appearance of the pancreas in LA group and small number of degeneration and necrosis in islet cells in STZ-DM+LA group (Figure 3). Histopathological evaluations of liver and kidney tissues are shown in Table 4 and Table 5.

In this present study, we investigated beneficial effects of Lupinis albus L. seed' roasting ethanol extract on diabetic rats. In the control and LA groups, liver, kidney and pancreas were normal histologic appearance. Severe degenerations were observed in the liver, kidney and pancreas tissues in the STZ group diabetic rats. Rats administered with Lupinus albus L. seed extract along with STZ showed that near normal appearance with regeneration liver, kidney and pancreas, which indicates the significant protection offered by Lupinus albus L. seed extract against the diabet. In this group, serious degeneration was not observed as well as in the STZ group. The increased formation of lipid peroxides and associated ROS leads to damage in membrane integrity and the other pathological changes in liver, kidney and pancreas.

\section{Conclusion}

These results indicate the role of Lupinus albus L. seed extract might as antidiabetic, antioxidant and reducing of the oxidative stress and lipid peroxidation. Extracted after Lupinus albus seed' roasting is a pioneer in literature and the use of LA in ethnomedicine for diabetes.

\section{Compliance with ethical standards}

\section{Acknowledgments}

BAY was the experiment leader and responsible for experimental, project design and applications. BAY and AE performed most of the experiments. SK made contributions as preparation of extract. SY carried out the histopathological studies of tissues. All authors read the final manuscript.

\section{Disclosure of conflict of interest}

The authors have no financial or personal relationships that could inappropriately influence or bias the content of the paper.

\section{Statement of ethical approval}

All efforts were made to minimize the number of animals and their suffering in this study through following the guidelines released by Ataturk University (TURKEY/Erzurum) policy on Animal Care and Use. The ethical norms were obtained prior to start study for Ethic Committee (No: 06.03.2014 36643897-203-ATA-44 Turkey/Erzurum).

\section{References}

[1] Bouchoucha R, Ben Fradj BK, Bouchoucha M, Akrout M, Feki M and Kaabachi N. (2016). Anti-hyperglycemic and anti-hyperlipidemic effects of Lupinus albus in Type 2 diabetic patients: A randomized double-blind, placebocontrolled clinical trial. Int J Pharmacol, 12(8), 830-837.

[2] Telli A, Esnault MA and Khelil AOEH. (2016). An ethnopharmacological survey of plants used in traditional diabetes treatment in south-eastern Algeria (Ouargla province). J Arid Environ, 127(1), 82-92.

[3] Salimifar M, Fatehi-Hassanabad Z and Fatehi M. (2013). A review on natural products for controlling type 2 diabetes with an emphasis on their mechanisms of actions. Curr Diabetes Rev, 9(1), 402-411. 
[4] Kinder DH and Knecht KT. (2011). Lupine (Lupinus caudatus L., Lupinus albus L.) seeds: History of use, use as an antihyperglycemic medicinal, and use as a food. In Preedy VR, Watson RR and. Patel VB. eds. Nuts and Seeds in Health and Disease Prevention, Elsevier, 711-716.

[5] Parmaki S, Vyrides I, Vasquez MI, Hartman V, Zacharia I, Hadjiadamou I and Koutinas M. (2018). Bioconversion of alkaloids to high-value chemicals: Comparative analysis of newly isolated lupanine degrading strains. Chemosphere, 193(1), 50-59.

[6] Cabello-Hurtado F, Keller J, Ley J, Sanchez-Lucas R, Jorrín-Novo JV and Aïnouche A. (2016). Proteomics for exploiting diversity of lupin seed storage proteins and their use as nutraceuticals for health and welfare. Journal of Proteomics, 143, 57-68.

[7] Lammi C, Aiello G, Vistoli G, Zanon C, Arnoldi A, Sambuy Y and Ranaldi G. (2016). A multidisciplinary investigation on the bioavailability and activity of peptides from lupin protein. J Funct Foods, 24, 297-306.

[8] Matsui R, Honda R, Kanome M, Hagiwara A, Matsuda Y, Togitani T and Terashima M. (2018). Designing antioxidant peptides based on the antioxidant properties of the amino acid side-chains. Food Chemistry, 245, 750-755.

[9] Sarangarajan R, Meera S, Rukkumani R, Sankar P and Anuradha G. (2017). Antioxidants: Friend or foe?, Asian Pac J of Trop Med, 10, 1111-1116.

[10] Farhat Z, Browne RW, Bonner MR, Tian L, Deng F, Swanson M and Mu L. (2018). How do glutathione antioxidant enzymes and total antioxidant status respond to air pollution exposure? Environment International, 112, 287293.

[11] Placer ZA, Cushman LL and Johnson BC. (1966). Estimation of product of lipid peroxidation (malonyldialdehyde) in biochemical systems. Anal Biochem, 16, 359-364.

[12] Goth L. (1991). A simple method for determenation of serum catalase activity and revision of serum catalase activity and revision of reference range. Clin Chim Acta, 196, 143-152.

[13] Sun Y, Oberley LW and Li Y. (1988). A simple method for clinical assay of superoxide dismutase. Clin Chem, 34, 497-500.

[14] Matkovics B, Szabó L and Sz Varga I. (1988). Determination of enzyme activities in lipid peroxidation and glutathione pathways (in Hungarian). Laboratóriumi Diagnosztika, 15, 248-250, 1988.

[15] Fernandez V and Videla LA. (1988). Effect of acute and chronic ethanol ingestion on the content of reduced glutathione of varios tissues of the rat. Experientia, 37, 392-394.

[16] Bancroff JD and Cook HJ. (1984). Mammal of histological tecniques, Ed., Livingstone C, New York.

[17] Erbaş 0. (2015). Experimental diabetes model. FNG \& Bilim Tıp Dergisi, 1, 40-42.

[18] Grzesik M, Naparło K, Bartosz G and Sadowska-Bartosz I. (2018). Antioxidant properties of catechins: Comparison with other antioxidants. Food Chemistry, 241, 480-492.

[19] Martín-Gallán P, Carrascosa A, Gussinyé M and Domínguez C. (2003). Biomarkers of diabetes-associated oxidative stress and antioxidant status in young diabetic patients with or without subclinical complications. Free Radic Biol Med, 34, 1563-1574.

[20] Lyons TJ and Basu A. (2012). Biomarkers in diabetes: hemoglobin A1c, vascular and tissue markers. Translational Research, 159, 303-312.

[21] Bandeira SDM, Guedes GDS, Fonseca LJSD, Pires AS, Gelain DP, Moreira JCF and Goulart MOF. (2012). Characterization of blood oxidative stress in type 2 diabetes mellitus patients: increase in lipid peroxidation and SOD activity. Oxid Med Cell Longev, 13.

[22] Bouhajja H, Kacem FH, Abdelhedi R, Ncir M, Dimitrov JD, Marrakchi R and Ayadi H. (2017). Potential predictive role of lipid peroxidation markers for Type 2 diabetes in the Tunisian population. Can J Diabetes, 1-9.

[23] Asmat U, Abad K and Ismail K. (2016). Diabetes mellitus and oxidative stress-a concise review. Saudi Pharm J, 24, 547-553.

[24] Duenas M, Hernández T, Estrella I and Fernández D. (2009). Germination as a process to increase the polyphenol content and antioxidant activity of lupin seeds (Lupinus angustifolius L.). Food Chemistry, 117, 599-607. 
[25] Sosulski FW and Dabrowski KJ. (1984). Composition of free and hydrolyzable phenolic acids in the flours and hulls of ten legume species. J Agric Food Chem, 32, 131-133.

[26] Siger A, Czubinski J, Kachlicki P, Dwiecki K, Lampart-Szczapa E and Nogala-Kalucka M. (2012). Antioxidant activity and phenolic content in three lupin species. J Food Compost Anal, 25, 190-197.

[27] Yildirim BA, Kordali S, Yildirim S, Yildirim F and Ercisli S. (2017). Antidiabetic and antioxidant effects of Vitis vinifera L. CV. "kara erik" seed exctract in streptozotocin diabetic rats. Oxid Commun, 40, 209-219.

[28] Gill KK, Sandhu HS and Kaur R. (2015). Evaluation of lipid peroxidation and antioxidant status on fenvalerate, nitrate and their co-exposure in Bubalus bubalis. Pestic Biochem Physiol, 123, 19-23.

[29] Beutler E. (1989). Nutritional and metabolic aspects of glutathione. Annu Rev Nutr, 9, 287-302.

[30] Singh SP, Coronella JA, Benes H, Cochrane BJ and Zimniak P. (2001). Catalytic function of Drosophila melanogaster glutathione S-transferase DmGSTS1-1 (GST2) in conjugation of lipid peroxidation end products. Eur J Biochem, 268, 2912-2923.

[31] Sinclair AJ. (1993). Free radical mechanisms and vascular complications of diabetes mellitus. Diabetes Rev, 2, 7 10.

[32] Regoli F, Gorbi S, Frenzilli G, Nigro M, Corsi I, Focardi S and Winston GW. (2002). Oxidative stress in ecotoxicology: from the analysis of individual antioxidants to a more integrated approach. Mar Environ Res, 54, 419-423.

[33] Dubey N, Raina R and Khan AM. (2012). Toxic effects of deltamethrin and fluoride on antioxidant parameters in rats. Fluoride, 45, 242-246.

[34] Hertwig B, Steb P and Feierabend J. (1992). Light dependence of catalase synthesis and degradation in leaves and the influence of interfering stres conditions. Plant Physiol, 100, 1547-1553.

[35] Aly N, Gendy K, Mahmoud F and El-Sebae A. (2010). Protective effect of vitamin C against chlorpyrifos oxidative stress in male mice. Pest Biochem Physiol, 97, 7-12.

\section{How to cite this article}

Apaydin Yildirim B, Ertekin A, Kordali S and Yildirim S. (2020). Antidiabetic and antioxidant effects of Lupinus albus L. seed roasting ethanol extract in streptozotocin diabetic rats. World Journal of Advanced Research and Reviews, 7(2), 07-16. 